\title{
Knowledge, attitude, and practice of breast Cancer among nurses in hospitals in Asmara, Eritrea
}

\author{
Amanuel Kidane Andegiorgish ${ }^{1 *}$, Eyob Azeria Kidane ${ }^{1}$ and Merhawi Teklezgi Gebrezgi ${ }^{2}$
}

\begin{abstract}
Background: Breast cancer accounted for 1.03\% of all deaths in 2014 in Eritrea. Yet the knowledge, attitude, and practice (KAP) of the population in general or the health personnel in the country in relation to the disease, remains unknown. Hence, this study was designed to assess the KAP regarding breast cancer among female nurses working in ten hospital wards in Asmara, Eritrea.

Methods: This was a cross-sectional study conducted among 414 nurses. Descriptive statistics, t-test, and ANOVA were used to evaluate the KAP of the nurses.

Results: Nurses' knowledge about the possible risk factors of breast cancer was low but the nurses knew the signs and symptoms of breast cancer since each sign or symptom was mentioned by $>50 \%$ of them. The practice of breast cancer screening, however, was low (only 30 and $11.3 \%$ practiced clinical breast examination and mammography respectively). Respondents' family history of breast cancer, having breast problems, their professional level and unit where they worked were associated with the KAP of nurses about breast cancer.

Conclusion: Training programs could help to increase the nurses' knowledge about the risk factors of breast cancer and practice of breast cancer screening. This could also help to increase the knowledge of the public about breast cancer.
\end{abstract}

Keywords: Breast cancer, Knowledge, Attitude, Practice, Nurse, Asmara, Eritrea

\section{Background}

Breast cancer is a major, life-threatening, public health concern. Long-term increase in the incidence of the disease has been observed in both developed and developing countries [1]. It is the most common cause of cancer mortality among women, accounting for $16 \%$ of cancer deaths in adult women [2].

In Eritrea, 370 women died from breast cancer in 2014 accounting for $1.03 \%$ of total deaths in that year giving an age-adjusted death rate of 21.40 per 100,000 of population [3]. Other source shows similar figures, with increasing rates in recent years in the country [4]. All malignant neoplasms of the breast in all age groups of women reported from all health facilities in Eritrea in

\footnotetext{
* Correspondence: akidane2016@gmail.com

${ }^{1}$ Department of Epidemiology and Biostatistics, Asmara College of Health

Sciences, School of Public Health, P.O.Box: 8566, Asmara, Eritrea

Full list of author information is available at the end of the article
}

the last 13 years (2004-2016) show a steady growth, with minor fluctuations in 2005 and 2009 (Health Information Management System of the Ministry of Health).

Breast cancer risk factors include increased age, genetic mutation, early menstrual period, late or no pregnancy, starting menopause after age 55 , not being physically active, being overweight or obese after menopause, having dense breast, using combination hormone therapy, taking oral contraceptives, personal history of breast cancer, personal history of certain non-cancerous breast diseases, a family history of breast cancer, previous treatment using radiation therapy and drinking alcohol [5]. Adequate knowledge about the signs and symptoms and early breast cancer detection through breast self-examination (BSE) or clinical breast examination (CBE) or mammogram, is crucial to reducing breast cancer-related morbidity and mortality.

(c) The Author(s). 2018 Open Access This article is distributed under the terms of the Creative Commons Attribution 4.0 International License (http://creativecommons.org/licenses/by/4.0/), which permits unrestricted use, distribution, and reproduction in any medium, provided you give appropriate credit to the original author(s) and the source, provide a link to the Creative Commons license, and indicate if changes were made. The Creative Commons Public Domain Dedication waiver (http://creativecommons.org/publicdomain/zero/1.0/) applies to the data made available in this article, unless otherwise stated. 
Information is needed to identify the underlying factors that might influence nurses' own practice of early detection methods of breast cancer. Empowering nurses with information about early detection methods and their related benefits could help in advancing their skills in performing breast self-examination and expanding their role as client educators [6]. Education and awareness need to be culturally appropriate and targeted towards the relevant population, because this may contribute towards an increase early presentation so that highest benefit can be gained [7, 8]. Health care providers, especially those who come in regular contact with women, can play an important role in providing the information regarding breast cancer [9].

Several cross-sectional studies on Knowledge Attitude and Practice (KAP) of breast cancer have been done among nurses in Nigeria [10-13] Ethiopia [14], Turkey [15] Jordan [16, 17], India [18], United Arab Emirates [19], Saudi Arabia [20] and Singapore [21]. Nurses KAP on breast cancer was ranging from relatively low to as high as $100 \%$. There were varying responses in attitude, knowledge of breast cancer screening methods and practice.

Previously, studies on the clinical aspects of breast cancer have been conducted in Eritrea [22-24]. Yet, no published study is available about the KAP of breast cancer among nurses in the country. The aim of this study was, therefore, to assess the (1) nurses' knowledge of breast cancer risk factors, (2) nurses' knowledge of breast cancer signs and symptoms, and (3) nurses' knowledge and practice of breast cancer examinations among female nurses working in ten hospital wards in Asmara. The information obtained could help to initiate interventions to address the gaps in KAP of nurses towards breast cancer. Ultimately, it is hoped that an improved KAP of nurses will contribute towards educating the public about the risk factors and early detection of breast cancer and, thereby, reduce morbidity and mortality due to breast cancer in the population.

\section{Methods}

\section{Study design and study population}

This was a cross-sectional study designed to assess the KAP of nurses on breast cancer. It was conducted among nurses whose qualifications included certificate, diploma, and degree and who were working in ten hospital wards in Asmara, the capital of Eritrea. All the nurses in the selected health facilities and wards were invited to participate in the study. Majority of the nurses working in the surveyed hospital wards were females.

\section{Data collection}

Knowledge of breast cancer among the participants was assessed based on knowledge on risk factors of breast cancer, signs and symptoms of breast cancer and knowledge on BSE, CBE, and mammography. The assessment was done by scoring breast cancer knowledge computed by giving " 1 " to the correct answer, and " 0 " for the wrong and 'do not know' answers. Furthermore, a percent knowledge index (PKI) was calculated for each nurse by summing the number of correct answers for all the variables and calculating the percentage of the correct answers. Furthermore, attitude was assessed by asking respondent about their opinions in regards to whether breast cancer is curable, how they would feel if they develop breast cancer and what they would do if they develop BC. Practice was assessed on what respondents do to detect early symptoms and signs of BC.

\section{Data analysis}

Data was collected by a pretested, questionnaire. List of study subjects was obtained initially from the Human Resource Management (HRM) office of the studied hospital wards, and after verbal consent was obtained, an interviewer guided self-administered questionnaire was used to collect the data. Collected data were checked for errors and data entry was completed using census survey processing (CSPro) software. Data were analyzed using the statistical package for social sciences (SPSS version 20) software. Descriptive statistics were used for data presentations. Association between categorical variables were explored using Chi-square. Quantitative analysis was performed using t-test for binary variables and ANOVA for more than two variables. $P<0.05$ was considered statistically significant.

\section{Ethical approval}

The study was approved by the Research and Ethics Committee of Asmara College of Health Sciences and Eritrean National Commission for Higher Education. An official letter was sent to concerned hospital directors and oral informed consent was obtained from the study subjects prior to questionnaire administration.

\section{Results}

A total of 427 nurses were approached to participate in this study. The complete response rate was $97 \%$ and so a total of 414 nurses' responses were included in the data analysis. The mean age of participants was $33.85 \pm 11.60$ (min 19 and max 69 years). Nearly half $(48.6 \%)$ of the participants were associate nurses. Similarly, half of the respondents (51\%) were unmarried. More than nine-tenths of study participants had no family history of breast cancer or no personal history of breast problems (Table 1). 
Table 1 Socio-demographic characteristics of nurses working in ten health facilities in Asmara, Eritrea

\begin{tabular}{|c|c|c|}
\hline Variable & Frequency & Percent \\
\hline \multicolumn{3}{|l|}{$\overline{\text { Age }}$} \\
\hline $19-29$ & 222 & 53.6 \\
\hline $30-39$ & 65 & 15.7 \\
\hline $40-49$ & 63 & 29.7 \\
\hline$>=50$ & 64 & 31.7 \\
\hline \multicolumn{3}{|l|}{ Marital Status } \\
\hline Single & 212 & 51.2 \\
\hline Ever married & 202 & 48.8 \\
\hline \multicolumn{3}{|l|}{ Religion } \\
\hline Muslim & 35 & 8.5 \\
\hline Christian & 379 & 91.5 \\
\hline \multicolumn{3}{|l|}{ Family Hx of Breast Cancer } \\
\hline Yes & 32 & 7.7 \\
\hline No & 382 & 92.3 \\
\hline \multicolumn{3}{|l|}{ Having breast problem } \\
\hline Yes & 20 & 4.8 \\
\hline No & 394 & 95.2 \\
\hline \multicolumn{3}{|l|}{ Professional Level } \\
\hline Associate Nurse & 201 & 48.6 \\
\hline Registered Nurse & 170 & 41.1 \\
\hline BSN & 43 & 10.4 \\
\hline \multicolumn{3}{|l|}{ Unite of Work } \\
\hline Orotta MCH & 38 & 9.1 \\
\hline Private hospital & 44 & 10.6 \\
\hline Medical wards & 162 & 38.9 \\
\hline Surgical Ward & 50 & 12.0 \\
\hline Community hospitals & 82 & 19.7 \\
\hline Ophthalmic hospital & 40 & 9.6 \\
\hline
\end{tabular}

BSN Bachelors of Science in Nursing, MCH Maternity Child Health

\section{Knowledge about risk factors of breast cancer}

Table 2 shows the responses of the nurses about the risk factors of breast cancer. About $78 \%$ of the participants mentioned that smoking is a risk factor for breast cancer. Similarly, $76 \%$ stated that breastfeeding decreases the risk of breast cancer and $62 \%$ stated that drinking alcohol is a risk factor. About two thirds (69\%) agreed that breast cancer could be hereditary and $66 \%$ thought that its risk increases with advancing age. Approximately one-third of the nurses stated that having a first child when over 30 is a possible risk factor for breast cancer.

\section{Attitude towards breast cancer}

The attitude of the participants on breast lump was satisfactory, $342(82.2 \%)$ of the participants were willing to be examined by a male doctor for their breast (data not shown). Similarly, 348 (83.7\%) were willing to be examined by a doctor within one week suspecting of developing breast lump.

Regarding the first time diagnosis of breast cancer, the response of the participants was scared (61.8\%), 95.7\% consult a doctor, $10.1 \%$ use traditional medicine and $80.8 \%$ agree on Mastectomy (If necessary).

When the nurses were asked about their own overall risk of developing breast cancer, $22 \%$ thought that they were not at risk, $21.2 \%$ thought that they were at low risk, $11.1 \%$ at medium risk and $24 \%$ at high risk. The remaining $21.6 \%$ stated they don't know.

Nurses were also asked if they had any of the risk factors for developing breast cancer, $51.0 \%$ answered they had none of the risk factors, $18.8 \%$ mentioned having one risk factor, $8.2 \%$ having two risk factors and $4.8 \%$ having three or more risk factors. On the potential risk factors of breast cancer,51.0\% of the respondents answered none, while $18.8 \%$ mentioned are having one risk factor, $8.2 \%$ two risk factors and $4.8 \%$ three and more than three.

More than half $(53.6 \%)$ of the participants believed that that breast cancer occurs more commonly in old women. In addition, 235 (56.5\%) of the participants have thoughts that breast cancer is a curable disease. The overall understanding of the survival period (more than five years) after clinical diagnosed of having breast cancer was $59.4 \%$.

\section{Knowledge about signs and symptoms of breast cancer}

Table 3 shows that swelling or enlargement of the breast was the predominantly mentioned signs of breast cancer followed by pain or soreness of the breast. Similarly, more than $85 \%$ of the respondents stated that a lump in the breast, change in the size of the breast and discoloration/dimpling of the breasts are the major signs of breast cancer. Weight loss was the least $(58.17 \%)$ mentioned sign and symptom of breast cancer.

In addition, $56.5 \%$ of the participants thought that breast cancer is a curable disease. The overall understanding on the survival period (more than five years) after clinical diagnosis of having breast cancer was $59.4 \%$.

\section{Knowledge and practice of nurses about screening methods}

The knowledge of nurses on the correct age for initiation of breast self-examination was $75.8 \%$ and more than three quarters $(80 \%)$ of them reported that they knew how to perform BSE and less than half of them (42\%) knew the recommended frequency of conducting BSE.

Three-quarters $(75.5 \%)$ of the nurses said they practiced BSE. Of these, $60.6 \%$ practiced once a month, $7.2 \%$ 
Table 2 Knowledge about risk factors of breast cancer among nurses in Asmara, Eritrea

\begin{tabular}{|c|c|c|c|}
\hline Questions & Yes & Percentage (\%) & 95\% Confidence Interval \\
\hline Does breast cancer risk increases with advancing age & 276 & 66.35 & {$[61.79-70.90]$} \\
\hline Is breast cancer hereditary & 287 & 68.99 & {$[64.53-73.45]$} \\
\hline Is high fat diet a risk factor for breast cancer & 154 & 37.02 & {$[32.37-41.67]$} \\
\hline Is smoking a risk factor for breast cancer & 327 & 78.61 & {$[74.65-82.56]$} \\
\hline Is alcohol consumption a risk factor for breast cancer & 261 & 62.74 & {$[58.08-67.40]$} \\
\hline Is first child at age more than 30 a risk factor for breast cancer & 144 & 34.62 & [30.03-39.20] \\
\hline Is menarche below 11 years a risk factor for breast cancer & 105 & 25.24 & {$[21.05-29.43]$} \\
\hline Is late menopause a risk factor for breast cancer & 144 & 34.62 & [30.03-39.20] \\
\hline Is stress a risk factor for breast cancer & 151 & 36.30 & [31.66-40.93] \\
\hline Is larger breast a risk factor for breast cancer & 57 & 13.70 & [10.39-17.02] \\
\hline Does breast feeding decrease risk of breast cancer & 317 & 76.20 & {$[72.10-80.31]$} \\
\hline Is painless breast lump a risk factor for breast cancer & 267 & 64.18 & {$[59.56-68.80]$} \\
\hline Is null parity a risk factor for breast cancer & 165 & 39.66 & {$[34.95-44.38]$} \\
\hline Is obesity a risk factor for breast cancer & 140 & 33.65 & {$[29.10-38.21]$} \\
\hline Do oral contraceptive pills increase the risk of breast cancer & 219 & 52.64 & {$[47.83-57.46]$} \\
\hline Is trauma to breast a risk factor of breast cancer & 135 & 32.45 & {$[27.94-36.96]$} \\
\hline Does endogenous estrogen hormone increase the risk of breast cancer & 234 & 56.25 & {$[51.47-61.03]$} \\
\hline Do you think giving births $>4$ decreases risk of breast cancer & 125 & 30.05 & {$[25.63-34.47]$} \\
\hline Does physical activity decrease the risk of breast cancer & 158 & 37.98 & {$[33.30-42.66]$} \\
\hline
\end{tabular}

once every three months, $14.5 \%$ said they did BSE once a year, and $17.8 \%$ did not answer. The reasons given for not practicing BSE were; 'carelessness' (17.1\%), 'don't have breast problem' (14.2\%), 'unsure about its benefit' (8.2), 'don't know how to do it' (5.3), 'too frequent to practice' (2.9\%), 'don't feel comfortable doing it' (1.2\%) and 'don't think I need to do it regularly' (1\%).

Thirty percent of the nurses practiced CBE. Of these, $14.9 \%$ were examined only once and $13.3 \%$ three times and above. The majority (55.3\%) of those who did not practice $\mathrm{CBE}$ stated that they were reluctant because they had no signs and symptoms of breast cancer. Forty-seven nurses (11.3\%) (37\% of those aged $>40$ years) had undertaken mammography examination in their life and only $8.7 \%$ of the overall study participants knew that 40 was the correct age for starting mammography as a screening method.

In this study, age and religious affiliation of respondents were associated with knowledge on signs and symptoms of breast cancer. Marital status was not associated with the KAP of nurses. Having breast problems was associated with the KAP of nurses whereas having a

Table 3 knowledge about the signs and symptoms of breast cancer among nurses in Asmara, Eritrea

\begin{tabular}{|c|c|c|c|}
\hline Questions (Signs and symptoms mentioned) & Yes & $\%$ & 95\% Confidence Interval \\
\hline Lump in the breast & 358 & 86.06 & {$[82.72-89.40]$} \\
\hline Discharge from the breast & 344 & 82.69 & [79.05-86.34] \\
\hline Pain or Soreness in the breast & 368 & 88.46 & [85.38-91.54] \\
\hline Change in the size of the breast & 358 & 86.06 & {$[82.72-89.40]$} \\
\hline Discoloration/dimpling of the breast & 355 & 85.34 & {$[81.93-88.75]$} \\
\hline Ulceration of the breast & 327 & 78.61 & {$[74.65-82.56]$} \\
\hline Weight loss & 242 & 58.17 & {$[53.42-62.93]$} \\
\hline Changes in the shape of the breast & 337 & 81.01 & {$[77.23-84.79]$} \\
\hline Inversion/ pulling in of nipple & 288 & 69.23 & {$[64.78-73.68]$} \\
\hline Swelling or enlargement of the breast & 374 & 89.90 & {$[87.00-92.81]$} \\
\hline Lump under armpit & 319 & 76.68 & {$[72.61-80.76]$} \\
\hline Scaling / dry skin on nipple region & 273 & 65.63 & {$[61.05-70.20]$} \\
\hline
\end{tabular}


family history of breast cancer was only associated with the knowledge of risk factors. Nurses with bachelor's degree had the highest knowledge compared to registered and associated nurses. The place of work was also significantly associated with the knowledge about breast cancer risk factors and its symptoms; nurses who worked at the Orotta Maternity Hospital had the highest knowledge (Table 4).

Moreover, there was a significant association between the professional level of nurses and BSE practice $(p<$ 0.001 ) in which registered nurses had the highest practice $(82.40 \%)$, followed by associated nurses $(74.4 \%)$ and

Table 4 Bivariate analysis of factors associated with KAP of nurses in Asmara, Eritrea

\begin{tabular}{|c|c|c|c|c|}
\hline & $\mathrm{N}$ & $\begin{array}{l}\text { Knowledge of Risk Factors } \\
\text { (Mean } \pm \text { SD) }\end{array}$ & $\begin{array}{l}\text { Knowledge of Symptoms } \\
\text { (Mean } \pm \text { SD) }\end{array}$ & $\begin{array}{l}\text { Knowledge and practice about breast cancer screening } \\
\text { (Mean } \pm \text { SD) }\end{array}$ \\
\hline \multicolumn{5}{|l|}{ Age } \\
\hline $19-29$ & 222 & $49.47 \pm 19.06$ & $83.68 \pm 17.16$ & $69.82 \pm 17.06$ \\
\hline $30-39$ & 65 & $50.26 \pm 20.61$ & $78.46 \pm 18.47$ & $69.91 \pm 16.04$ \\
\hline $40-49$ & 63 & $44.62 \pm 23.44$ & $78.52 \pm 18.33$ & $69.66 \pm 21.23$ \\
\hline$>=50$ & 66 & $48.52 \pm 17.52$ & $85.00 \pm 20.62$ & $68.52 \pm 19.35$ \\
\hline$p$ value ${ }^{2}$ & & 0.333 & 0.042 & 0.961 \\
\hline \multicolumn{5}{|l|}{ Marital Status } \\
\hline Single & 212 & $49.32 \pm 19.95$ & $84.06 \pm 16.91$ & $71.23 \pm 14.25$ \\
\hline Ever married & 202 & $49.60 \pm 19.49$ & $80.45 \pm 19.24$ & $68.40 \pm 19.77$ \\
\hline$p$ value & & 0.889 & 0.050 & 0.103 \\
\hline \multicolumn{5}{|l|}{ Religion } \\
\hline Muslim & 35 & $48.71 \pm 16.72$ & $72.29 \pm 17.17$ & $66.35 \pm 15.82$ \\
\hline Christian & 379 & $48.73 \pm 20.09$ & $83.23 \pm 18.08$ & $69.96 \pm 13.55$ \\
\hline$p$ value & & 0.995 & 0.001 & 0.138 \\
\hline \multicolumn{5}{|c|}{ Family Hx of Breast Cancer } \\
\hline Yes & 30 & $61.48 \pm 15.64$ & $76.87 \pm 23.48$ & $65.65 \pm 18.29$ \\
\hline No & 384 & $47.71 \pm 19.78$ & $82.75 \pm 17.69$ & $70.02 \pm 17.88$ \\
\hline$p$ value & & 0.001 & 0.080 & 0.180 \\
\hline \multicolumn{5}{|c|}{ Having breast problem } \\
\hline Yes & 20 & $59.88 \pm 8.85$ & $73.00 \pm 19.49$ & $58.88 \pm 13.54$ \\
\hline No & 396 & $48.20 \pm 20.03$ & $82.77 \pm 18.07$ & $70.14 \pm 17.95$ \\
\hline P Value & & 0.014 & 0.019 & 0.006 \\
\hline \multicolumn{5}{|l|}{ Professional Level } \\
\hline Associate Nurse & 203 & $45.78 \pm 20.09$ & $82.36 \pm 17.31$ & $66.50 \pm 18.23$ \\
\hline Registered Nurse & 170 & $49.22 \pm 19.57$ & $82.26 \pm 20.02$ & $72.22 \pm 17.65$ \\
\hline BSN & 43 & $60.34 \pm 14.73$ & $82.09 \pm 15.21$ & $73.90 \pm 14.72$ \\
\hline P Value & & 0.001 & 0.996 & 0.002 \\
\hline \multicolumn{5}{|l|}{ Unite of Work } \\
\hline Orotta MCH & 38 & $63.60 \pm 12.50$ & $91.58 \pm 10.27$ & $71.35 \pm 15.85$ \\
\hline Private hospital & 44 & $54.80 \pm 20.60$ & $86.59 \pm 15.99$ & $73.48 \pm 11.55$ \\
\hline Medical wards & 162 & $49.06 \pm 21.91$ & $80.98 \pm 24.09$ & $68.38 \pm 13.60$ \\
\hline $\begin{array}{l}\text { Orotta Medical } \\
\text { Surgical }\end{array}$ & 50 & $36.67 \pm 15.71$ & $80.60 \pm 16.83$ & $68.57 \pm 12.44$ \\
\hline $\begin{array}{l}\text { Community } \\
\text { hospitals }\end{array}$ & 82 & $45.66 \pm 15.42$ & $76.71 \pm 20.31$ & $71.54 \pm 14.83$ \\
\hline $\begin{array}{l}\text { Ophthalmic } \\
\text { hospital }\end{array}$ & 40 & $45.97 \pm 19.97$ & $75.25 \pm 17.54$ & $66.39 \pm 13.19$ \\
\hline P value ${ }^{2}$ & & 0.001 & 0.001 & 0.093 \\
\hline
\end{tabular}

$1=T$-test $2=$ ANOVA 
bachelor science in Nursing (BSN) $(55.80 \%)$ (data not shown).

\section{Discussion}

There are four important findings in this study. Firstly, nurses' knowledge about the possible risk factors of breast cancer is a concern since many established risk factors of breast cancer were mentioned by less than $50 \%$ of them. Secondly, nurses had a good knowledge of the signs and symptoms of breast cancer in which each sign or symptom was mentioned by more than half of them. Thirdly, the practice of breast cancer screening was low and lastly, a family history of breast cancer, having breast problems, the professional level of nurses and the unit where they work predicts the KAP of nurses about breast cancer.

In some studies elsewhere, nurses' knowledge about the risk factors of breast cancer has been found to be low $[14,16,20]$ whilst other studies have reported nurses' knowledge about risk factors of breast cancer to be high [13]. The fact that there are many risk factors of breast cancer [5] and new factors have been found to be associated with breast cancer might have affected the knowledge of the nurses. The unit they work may influence their knowledge. In the present study, nurses who worked at Orotta Maternity Hospital had the highest knowledge about the risk factors of breast cancer while nurses who were working at Orotta surgical ward had the lowest knowledge. Therefore, efforts need to be taken to increase the knowledge of nurses about the risk factors of breast cancer. Short on-site courses prioritizing those nurses who work outside maternity units/ wards and nurses with associate level could help to update their knowledge.

In line with other studies $[11,15,20]$ nurses in this study were found to have a good knowledge of the signs and symptoms of breast cancer. Nurses who work in the Orotta Maternity Hospital had high (91.6\%) knowledge about the signs and symptoms of breast cancer.

Knowledge and attitude should be accompanied by practice. A gap in practice was identified in this study in which nurses were found to practice breast cancer screening infrequently. Nurses in this study reported practicing CBE and mammography less often. Only $30 \%$ of the nurses practiced clinical breast examination. This was similar to the findings from one study in Nigeria [11] and lower than a similar study in the same country [13]. Of all the nurses, only (11.3\%) had undertaken mammography examination. Mammography is the gold standard for early detection of breast cancer but is not recommended for countries with limited resources due to its cost and technical complexity [25]. The practice of BSE among the nurses in this study was lower than studies conducted elsewhere $[16,19]$ and higher than some other similar studies $[18,20]$.
There were some limitations in this study. Firstly, the practice of breast cancer screening was reported, but nurses may not adequately remember whether they have done breast cancer screening or not. Secondly, since our subjects were those nurses working in hospitals only, this result may not reflect the knowledge of nurses who work in health centers and small clinics. Despite these limitations, we discovered important gaps in KAP of hospital nurses about breast cancer.

\section{Conclusion}

This was the first study to assess the KAP of nurses' about breast cancer. Nurses were found to have good knowledge of the signs and symptoms of breast cancer but little knowledge about the risk factors of the disease. The practice of breast cancer screening among the nurses was low. Therefore, training programs to update nurses' knowledge about the risk factors of breast cancer and practice of breast cancer screening could potentially help in the practice of healthy habits among the nurses. This, indirectly, could also help to increase the knowledge and practice of the public about breast cancer.

\section{Abbreviations \\ BSE: Breast Self-Examination; BSN: Bachelor of Science in Nursing; CBE: Clinical Breast Examination; HRM: Human Resource Management; KAP: Knowledge Attitude and Practice}

\section{Acknowledgments}

The authors gratefully acknowledge the National Commission for Higher Education (NCHE) of Eritrea for financial support for this research. The authors appreciate the support of health facility directorates and head nurses. The authors would like to thank all the nurses who participated in this study for their kind cooperation.

\section{Funding}

This research was supported by Eritrea Research Fund (ERF).

\section{Availability of data and materials}

Pertinent data are presented in this manuscript. Additional data can be requested from the corresponding author upon reasonable request.

\section{Authors' contributions}

AKA led, wrote and drafted the manuscript. EAK wrote and drafted the manuscript. MTG reviewed the manuscript. All authors approved the final draft of the manuscript.

\section{Ethics approval and consent to participate}

This study was approved by the ethics committee of Ministry of Health of the State of Eritrea and National Commission for Higher Education. Written consent was obtained from all the participants.

\section{Consent for publication}

Not applicable.

\section{Competing interests}

The authors declare that they have no competing interests.

\section{Publisher's Note}

Springer Nature remains neutral with regard to jurisdictional claims in published maps and institutional affiliations. 


\section{Author details}

'Department of Epidemiology and Biostatistics, Asmara College of Health Sciences, School of Public Health, P.O.Box: 8566, Asmara, Eritrea. ${ }^{2}$ Department of Epidemiology, Robert Stempel College of Public Health and Social Work, Florida International University, 11200 SW 8th St, Miami, FL 33199, USA.

Received: 21 December 2017 Accepted: 10 July 2018

Published online: 31 July 2018

\section{References}

1. Wadler BM, Judge CM, Prout M, Allen JD, Geller AC. Improving breast Cancer control via the use of community health Workers in South Africa: a critical review. J Oncol 2011;2011:8. Article ID 150423. http://dx.doi.org/10. 1155/2011/150423

2. Anderson BO, Braun S, Lim S, Smith RA, Taplin S, Thomas DB. Early detection of breast cancer in countries with limited resources. Breast J. 2003;9(Suppl 2):S51-9.

3. World Health Ranking. Eritrea, Breast Cancer 2014. Available at: http://www. worldlifeexpectancy.com/eritrea-breast-cancer. Accessed on 5 Aug. 2017

4. Global health Statistics Bareast cancer in Eritrea. 2017. Available at: http:// global-disease-burden.healthgrove.com/l/33029/Breast-Cancer-in-Eritrea. Accessed on 5 Aug. 2017.

5. Center for Diseases Control and Prevention. 2016. Avaliable at: https://www. cdc.gov/cancer/breast/basic_info/risk_factors.htm. Accessed on 7 Aug. 2017.

6. Collaborative Group on Hormonal Factors in Breast Cancer. Familial breast cancer: collaborative reanalysis of individual data from 52 epidemiological studies including 58,209 women with breast cancer and 101,986 women without the disease. Lancet. 2001;358(9291):1389-99.

7. Stockton D, Davies T, Day N, McCann J. Retrospective study of reasons for improved survival in patient with breast cancer in east Anglia: earlier diagnosis or better treatment. BMJ. 1997;314:472-5.

8. Ersumo T. Breast cancer in an Ethiopian population, Addis Ababa. East Africa Journal of Surgery. 2006;11(1):81-6.

9. Thomas DB, Gao DL, Ray RM, Wang WW, Allison CJ, Chen FL, et al. Randomized trial of breast self-examination in shanghai: final results. J Nat Cancer Inst 2002;94(19):1445-1457.

10. Bello TO, Olugbenga-Bello Al, Oguntola AS, Adeoti ML, Ojemakinde OM. Knowledge and practice of breast cancer screening among female nurses and lay women in Osogbo. Nigeria West Afr J Med. 2011;30(4):296-300.

11. Odusanya $\mathrm{OO}$, Tayo OO. Breast cancer knowledge, attitudes and practice among nurses in Lagos, Nigeria. Acta Oncol. 2001;40(7):844-8.

12. Akhigbe $\mathrm{AO}$, Omuemu VO. Knowledge, attitudes and practice of breast cancer screening among female health workers in a Nigerian urban city. BMC Cancer. 2009:9:203.

13. Awodele O, Adeyomoye AA, Oreagba IA, Dolapo DC, Anisu DF, Kolawole $\mathrm{SO}$, et al. Knowledge, attitude and practice of breast cancer screening among nurses in Lagos University teaching hospital, Lagos Nigeria Nig Q J Hosp Med 2009:19(2):114-118.

14. Lemlem SB, Sinishaw W, Hailu M, Abebe M, Aregay A. Assessment of knowledge of breast Cancer and screening methods among nurses in university hospitals in Addis Ababa, Ethiopia, 2011. ISRN Oncol. 2013;2013: 470981.

15. Andsoy II, Gul A. Breast, cervix and colorectal cancer knowledge among nurses in Turkey. Asian Pac J Cancer Prev. 2014;15(5):2267-72.

16. Alkhasawneh IM. Knowledge and practice of breast cancer screening among Jordanian nurses. Oncol Nurs Forum. 2007;34(6):1211-7.

17. Madanat $\mathrm{H}$, Merrill RM. Breast cancer risk-factor and screening awareness among women nurses and teachers in Amman, Jordan. Cancer Nurs. 2002; 25(4):276-82.

18. Fotedar V, Seam RK, Gupta MK, Gupta M, Vats S, Verma S. Knowledge of risk factors and early detection methods and practices towards breast cancer among nurses in Indira Gandhi medical college, Shimla, Himachal Pradesh, India. Asian Pac J Cancer Prev. 2013;14(1):117-20.

19. Sreedharan J, Muttappallymyalil J, Venkatramana M, Thomas M. Breast selfexamination: knowledge and practice among nurses in United Arab Emirates. Asian Pac J Cancer Prev. 2010;11(3):651-4.

20. Yousuf SA, Al Amoudi SM, Nicolas W, Banjar HE, Salem SM. Do Saudi nurses in primary health care centres have breast cancer knowledge to promote breast cancer awareness? Asian Pac J Cancer Prev. 2012;13(9):4459-64

21. Seah M, Tan SM. Am I breast cancer smart? Assessing breast cancer knowledge among health professionals. Singap Med J. 2007;48(2):158-62.
22. Ghebrehiwet M, Paulos E, Andeberhan T. The role of combined ultrasonography and mammography in the diagnosis of breast cancer in Eritrean women with palpable abnormalities of the breast. J Eritrean Med Assoc. 2007;2(1):2-7.

23. Tesfamariam A, Parilla F, Paulos E, Mufunda J, Gebremichael A. Clinicohistopathological evaluation of breast masses and profle of breast diseases in Eritrea: a case of poor concordance between clinical and histological diagnosis. J Eritrean Med Assoc. 2008;3(1):32-5.

24. Tesfamariam A, Gebremichael A, Mufunda J. Breast cancer clinicopathological presentation, gravity and challenges in Eritrea, East Africa: management practice in a resource-poor setting. S Afr Med J. 2013, 103(8):526-8.

25. The International Network for Cancer Treatment and Research. Cancer - a neglected health problem in developing countries. Lancet. 2011;358:1389-99.
Ready to submit your research? Choose BMC and benefit from:

- fast, convenient online submission

- thorough peer review by experienced researchers in your field

- rapid publication on acceptance

- support for research data, including large and complex data types

- gold Open Access which fosters wider collaboration and increased citations

- maximum visibility for your research: over $100 \mathrm{M}$ website views per year

At $\mathrm{BMC}$, research is always in progress.

Learn more biomedcentral.com/submissions 